Portland State University

PDXScholar

$5-27-2008$

\title{
Comparing Pixel- and Object-Based Classification Methods for Determining Land-Cover in the Gee Creek Watershed, Washington
}

Tyler Vick

Portland State University

Follow this and additional works at: https://pdxscholar.library.pdx.edu/geog_masterpapers

Part of the Geographic Information Sciences Commons, Nature and Society Relations Commons, and the Physical and Environmental Geography Commons

Let us know how access to this document benefits you.

\section{Recommended Citation}

Vick, Tyler, "Comparing Pixel- and Object-Based Classification Methods for Determining Land-Cover in the Gee Creek Watershed, Washington" (2008). Geography Masters Research Papers. 22.

https://pdxscholar.library.pdx.edu/geog_masterpapers/22

10.15760/geogmaster.22

This Paper is brought to you for free and open access. It has been accepted for inclusion in Geography Masters Research Papers by an authorized administrator of PDXScholar. Please contact us if we can make this document more accessible: pdxscholar@pdx.edu. 
Comparing Pixel- and Object-Based Classification Methods for Determining Land-Cover in the Gee Creek Watershed, Washington

\author{
Tyler Vick
}

Submitted for partial fulfillment of Master of Science degree in Geography

Portland State University

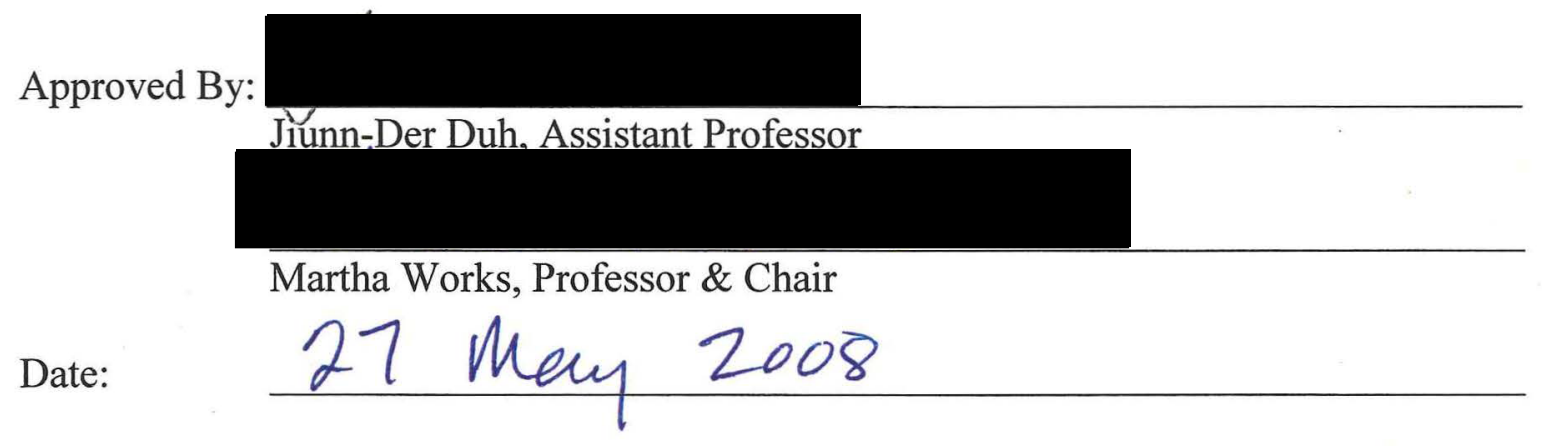




\section{Abstract}

This study analyzes land-cover types in the Gee Creek Watershed of southern Washington using the pixel-based and object-based image analysis approaches. Landsat imagery has traditionally been used for pixel-based classification and change detection in land-cover studies. In recent years, the availability of high-resolution satellite and aerial imagery have enabled for land-cover classification to occur at scales not possible using traditional Landsat imagery. High-resolution aerial imagery of 1 meter or greater has become readily available for free. Yet, commonly found black and white (or panchromatic) aerial imagery is without the multiple spectrum bands found in Landsat imagery, thereby limiting the accuracy of traditional pixel-based multispectral classification approaches. Instead, object-based image classification can be used as an alternative analysis approach for determining land-cover types on high-resolution imageries.

This paper examines and compares two traditional Landsat pixel-based techniques with the high-resolution object-based approach. Both approaches are used to conduct land-cover classification within the highly variable landscape of the Gee Creek Watershed. The high variability found within the Watershed is the result of recent years of development that have changed the landscape from predominantly forest and agriculture to one of the fastest growing suburbia's outside the Portland-Vancouver metropolitan area. Two pixel-based classification analyses are conducted using Landsat imagery; supervised classification of multispectral bands and unsupervised classification of transformed Tasseled Cap bands. These traditional approaches are then compared to object-based classification using 1 meter resolution natural color aerial imagery obtained 
from the United States Department of Agriculture. The result of this analysis suggests that Landsat pixel-based approaches are only suitable for determining general land-cover types, whereas the use of object-based classification on high-resolution imagery resulted in increased accuracy and ultimately led to a higher number of land-cover classes being distinguished. 


\section{Table of Contents}

INTRODUCTION

COMPARING PIXEL- AND OBJECT-BASED CLASSIFICATION METHODS .. 6

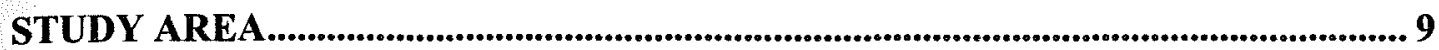

IMAGE DATA \& METHODOLOGY .................................................................. 12

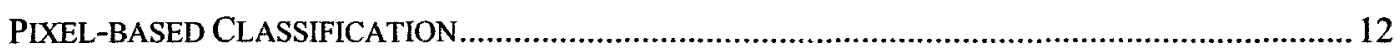

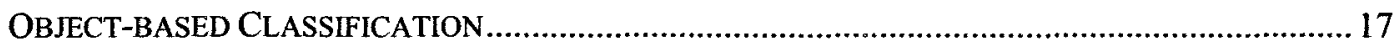

ACCURACY OF CLASSIFICATION RESULTS ................................................ 21

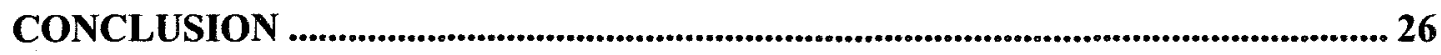

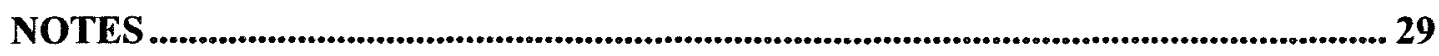

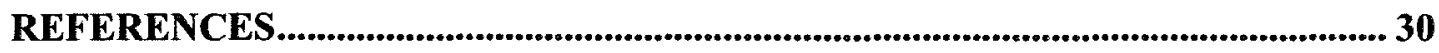




\section{Introduction}

Over the past few decades, methods utilizing multispectral satellite imagery for extraction of land-cover types were largely founded on pixel-based approaches, such as supervised and unsupervised classification algorithms (Traux et al, 2006). However, traditional satellite imagery sources, such as Landsat, contain a spatial resolution of 30-70 meters, allowing for the classification of only general land-cover types (Welch, 1982). In recent years, the availability of high-resolution satellite and aerial imagery of 1 meter or higher have enabled for land-cover classification to occur at scales not possible using traditional Landsat imagery. Instead, object-based image classification can be used as an alternative analysis approach for determining land-cover types on high-resolution imageries, thereby providing new opportunities for mapping detailed land-covers.

The goal of this paper is to examine and compare two traditional pixel-based classification approaches with the object-based approach. Two pixel-based classification analyses are conducted using Landsat Enhanced Thematic Mapper Plus (ETM+) imagery; supervised classification of ETM+ multispectral bands and unsupervised classification of transformed Tasseled Cap (TC) bands. These traditional approaches are then compared to object-based classification using 1 meter resolution natural color aerial imagery obtained from the US Department of Agriculture's (USDA) National Agricultural Imagery Program (NAIP). Both approaches are used to conduct land-cover classification within the highly variable landscape of the Gee Creek Watershed located in southern Washington. The high variability found within the watershed is the result of recent years of development that have changed the landscape from predominantly forest and 
agriculture to one of the fastest growing suburbia's outside the Portland-Vancouver metropolitan area.

This paper first introduces pixel- and object-based classification methods. It then discusses the unique physical characteristics of the Gee Creek Watershed, including a background discussion on the watershed's history of land-use over time. This discussion is followed by a description of the image data used in this study, as well as a detailed description on the methodology used for both the pixel- and object-based classification approaches. An accuracy assessment is then discussed, which provides the percentage of land-cover types correctly classified, along with summary statistics on the acreages of land-cover types classified. The paper concludes with a discussion on the classification approaches utilized, including future uses and potential limitations for using each method at the watershed level.

\section{Comparing Pixel- and Object-based Classification Methods}

Simple spectral-based classifiers were first developed in the 1970s for use with multispectral data (Traux et al, 2006). The objective of traditional image classification procedures is to categorize all pixels in an image into land-cover classes. In most cases, multispectral data are used to perform the classification, which uses the spectral pattern present within the data for each pixel as the numerical basis for categorization. The recognition of a spectral signature is based on the analogy that different feature types manifest different combinations of Digital Numbers (DN) based on their inherent spectral reflectance and emittance properties (Oruc et al, 2006). The term signature refers to the set of radiance measurements obtained in the various wavelength bands for each pixel (Oruc et al, 2006). Both unsupervised and supervised spectral-based approaches are 
routinely applied to remotely sensed data based on spectral or pixel-based schemes. However, recent investigations have shown that a pixel-based analysis of high-resolution imagery has explicit limits, such as accurately delineating landscape objects that have internal reflectance variation (Meinel and Neubert, 2004).

Object-based classification is a new classification method (Lewinski and Zaremski, 2004). It is utilized by software packages that include new image-analysis tools, such as eCognition (Definiens Imaging, 2006) and SPRING (Brazil's National Institute for Space Research, 2006). Despite some early research activities (e.g., Kettig and Landgrebe, 1976), image segmentation was established late in the field of remote sensing. First beginning with the availability of very high-resolution imagery $(<1 \mathrm{~m})$ and their characteristics (high level of detail, spectral variance, etc.) this method has become popular as a common variant of data interpretation (Meinel and Neubert, 2004). In contrast to traditional pixel-based approaches, groups of pixels called objects are examined during the classification process. Objects are created during the segmentation process; when the images are subdivided into groups of pixels which have similar local contrast values. Objects that share common properties are then encompassed into classes. A scale factor, which determines the size of the objects, is the basic parameter in their creation. The elements analyzed are not only the spectral values of an object, but also its shape, texture and course of its boundary with other neighboring objects. By applying the correct scale factor, it is possible to obtain objects with boundaries the paths of which closely resemble those in the visual interpretation of the image. It is acceptable that the segmentation of the image takes place in multiple phases (Lewinski and Zaremski, 2004). Based on the already existing objects, new higher order (larger) or lower-order (smaller) 
objects are created. Using object-based classification techniques, common problems associated with pixel-based image classification can be overcome, such as taking into account the characteristics of larger, interconnected areas through neighborhood and hierarchy relations (e.g. Meinel et al, 2001).

The object-based approach in this analysis utilizes the free segmentation software product SPRING, which was developed by Brazil's National Institute for Space Research (INPE). SPRING is an object-oriented data model image classification software similar to eCognition. Segmentation is the first and important phase in the SPRING software and its aim is to create meaningful objects. The detection of objects during the segmentation phase exhibit multi-scale behavior, where a number of small objects can be aggregated to form large objects constructing a semantic hierarchy. Likewise, a large object can be split into a number of smaller objects which basically leads to two main approaches to object-based image analysis: A top-down and a bottom-up approach (Oruc et al, 2006). Segmentation tests between SPRING and eCognition have shown no notable differences between the ability of the software packages to derive image objects from land-cover types (Meinel and Neubert, 2004; US Fish and Wildlife, 2006).

After the segmentation is performed, the software takes advantage of innovative algorithms based on region-based classification by neural networks (Bins et al, 1993). These classifiers include the Isoseg algorithm used for non-supervised data grouping, the Bhattacharya algorithm, which requires user interaction through training, and the ClaTex algorithm that uses regions texture attributes from a segmented image. Both region classifiers not only use the spectral information of each pixel, but also the spatial information involving the relationship of pixels to their neighbors. As a result, region 
classifiers attempt to simulate the behavior of a photo-interpreter, when recognizing homogeneous areas in the images, based on spectral and spatial image properties (Brazil's National Institute for Space Research, 2006).

\section{Study Area}

The Gee Creek Watershed occupies a 10,700-acre basin located 10 miles north of the Portland metropolitan area in Clark County, Washington (Figure 1). Elevations within the watershed range from 300 feet to less than 8 feet at the Columbia River. The Gee Creek, a perennial stream tributary of the Columbia River, runs approximately 10 miles in total length. The creek originates on the gently sloping topography along Interstate 5, flows west through canyons and the City of Ridgefield, and then into a series of Columbia River floodplain lowland lakes and ponds on the Ridgefield National Wildlife Refuge (RNWR), before reaching the Columbia River (Clark County Public Works, 2004). The majority of the land within the Gee Creek Watershed is privately owned (Clark County Assessment and GIS, 2007).

The upland portions of the Gee Creek Watershed were historically dominated by native conifer forest (Bureau of Land Management, 2007). Patches of oak woodland were also historically present in the watershed and are still found on the Gee Creek lowlands, associated with rock outcroppings and floodplain shoreline bluffs (Cornelius, 2006). A number of oak groves can also be found in the upper watershed where small woodland and prairie patches may have occurred historically.

The Gee Creek watershed has been subject to early and direct land uses for the past 169 years (Cornelius, 2006). The early town of Union Ridge was incorporated and 
Figure 1: The Gee Creek Watershed located in southern Washington (Image Source: USDA NAIP, 2006)

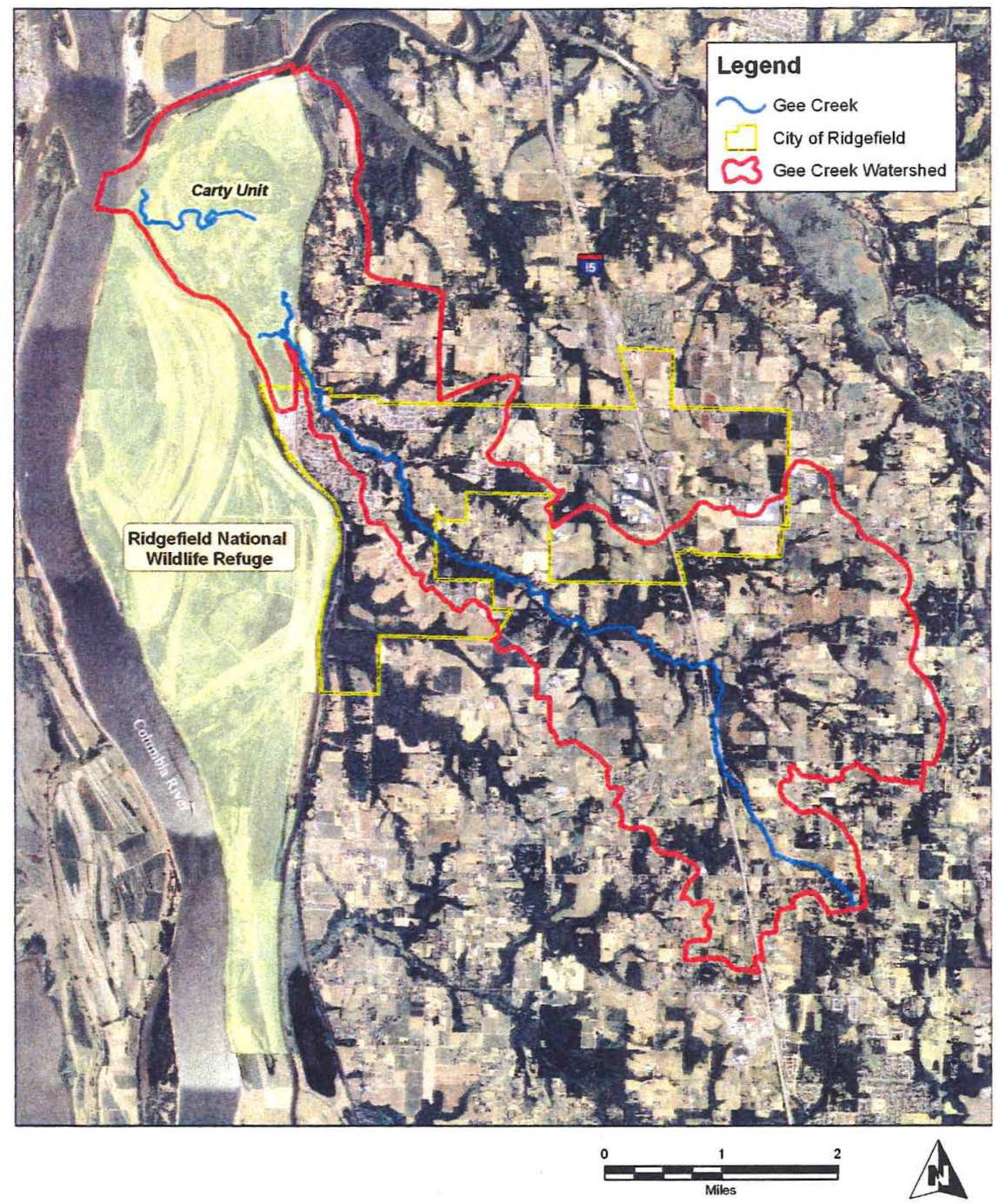

renamed as the City of Ridgefield in 1909 (Fort Vancouver Historical Society, 19611965). During this time, rural and farm land uses were predominate across the watershed, with dairy industry and potato farming leading the watershed's agricultural use (Columbian Newspaper, 1953). Over the past few decades, commercial farming has given way to rural-residential land uses. Most recently, rapid conversion to industrial, suburban and urban land uses has occurred, as a result of the annexation and growth of the City of Ridgefield along the middle and upper portions of the watershed (City of 
Ridgefield, 2006). Recent housing developments, new rural residences, and industrial development can be seen near the I-5 corridor in the upper portion of the watershed. Ridgefield's population is estimated to grow nearly 10 fold over the next 20 years to approximately 24,000 by 2024 (Cornelius, 2006).

In recent years a surge in restoration and preservation efforts within the watershed has occurred. These efforts are largely in response to the negative impacts due to recent vegetation clearing and development directly associated with the growth of the city of Ridgefield. However, historical land use management practices (e.g., forest clearing) have also attributed to the poor health of the watershed's streams. Organizations involved in ongoing restoration efforts include the US Fish and Wildlife, the Washington State Department of Ecology, the Washington State University Clark County Extension, Portland State University, Friends of Ridgefield National Wildlife, and the Friends of Gee Creek.

Accurately and timely compilation of land-cover maps of the Gee Creek Watershed will help support the US Fish and Wildlife's efforts in determining areas along the watershed's creeks that lack adequate conifer and deciduous land-cover and primarily consist of urban and bare land. The presence of tree canopy cover and vegetated landscaping within the watershed are important, for they provide shade, wood debris, and litter, which help regulate stream temperature and provide necessary debris for aquatic habitat. The main result of the study is to identify which classification methods are better. Land-cover maps derived from satellite or aerial imagery, coupled with additional topographic and land use data, will ultimately support efforts at targeting watershed landowners for preservation and restoration. 


\section{Image Data \& Methodology}

\section{Pixel-based Classification}

A Landsat ETM+ image from September 22, 1999 was used to conduct the pixelbased classification (Figure 2). The 30-meter resolution Landsat image was obtained via a free download from the Landsat.org website. The software product ERDAS IMAGINE V9.1 was utilized for all phases of processing for the pixel-based classification procedures. In preparation for classification, spectral bands $1-5$ and 7 were layer stacked. The thermal and panchromatic bands, 6 and 8 respectively, were not used in classification. The detection characteristics of the Landsat ETM+ bands used in the analysis are provided in Table 1. The second and final phase of image preprocessing consisted of masking the layer stacked Landsat image to the boundaries of the Gee Creek

Figure 2: September 22, 1999 Landsat ETM+ image

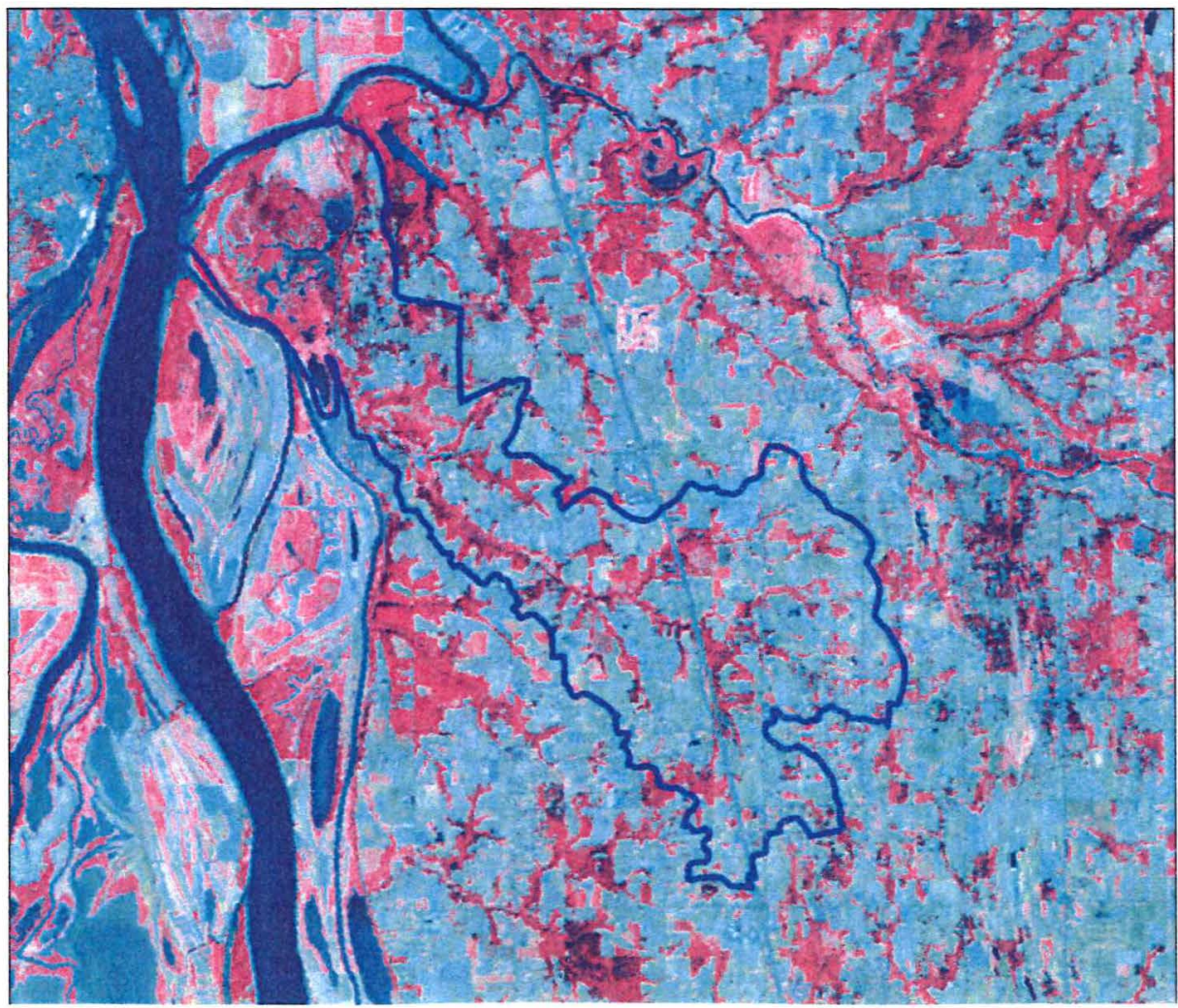


Watershed. This procedure was completed to ensure that the classification algorithms would not detect the spectral properties of pixels outside the watershed's boundary, thereby complicating the classification process.

Table 1: Landsat 7 ETM+ band detection characteristics (Oruc et al, 2006)

\begin{tabular}{|c|c|l|}
\hline Band & Wavelength & \multicolumn{1}{|c|}{ Detection Characteristics } \\
\hline 1 & $0.45-0.52$ & Blue: penetrate water \\
\hline 2 & $0.52-0.60$ & Green: healthy vegetation \\
\hline 3 & $0.63-0.69$ & Red: photosynthetic activity \\
\hline 4 & $0.76-0.90$ & Near IR: plant vigor \\
\hline 5 & $1.55-1.75$ & Mid IR: water in plants \\
\hline 7 & $2.08-2.35$ & Shortwave IR: mineral/rock types \\
\hline
\end{tabular}

Table 2: Classification schemes of pixel-and object-based classification

\begin{tabular}{|l|l|}
\hline \multicolumn{2}{|c|}{ Land-Cover Classes } \\
\hline Pixel-Based & Object-Based \\
\hline Water & Water \\
\hline Coniferous & Coniferous \\
\hline Deciduous & Deciduous \\
\hline Shrub & Shrub \\
\hline \multirow{2}{*}{ Ag/Grass } & Agriculture \\
\cline { 2 - 2 } & Reed Canary Grass \\
\hline \multirow{2}{*}{ Urban/Bare Soil } & Urban \\
\cline { 2 - 2 } & Bare Soil \\
\hline
\end{tabular}

An initial classification scheme was created identifying the 10 most relevant landcover types within the watershed. Anderson's land-use land-cover classification system (Anderson et al, 1976) was utilized as a guide for determining the Level 1 and II landcover types. However, it became clear early on in the classification analysis that the 30meter resolution of the Landsat ETM+ image would inhibit the use of 10 classes. This limitation is primarily due to the high variability of land-cover types present in the Gee 
Creek Watershed over relatively short distances (e.g., $<30 \mathrm{~m}$ ). As a result, the initial 10

land-cover classes were reduced to 6 general land-cover types (Table 2, left column).

Figure 3: Band combinations utilized during training site selection in supervised classification (the box delineates the area shown in Figure 4)

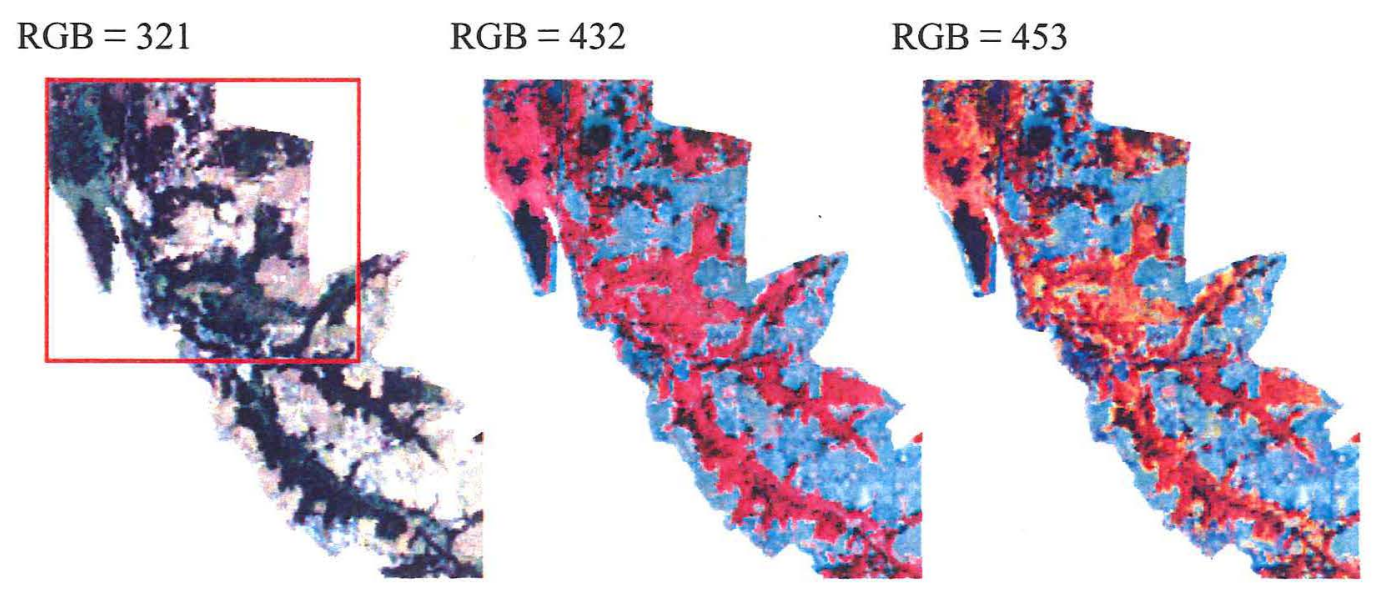

Figure 4: A subset of training sites used in the supervised classification

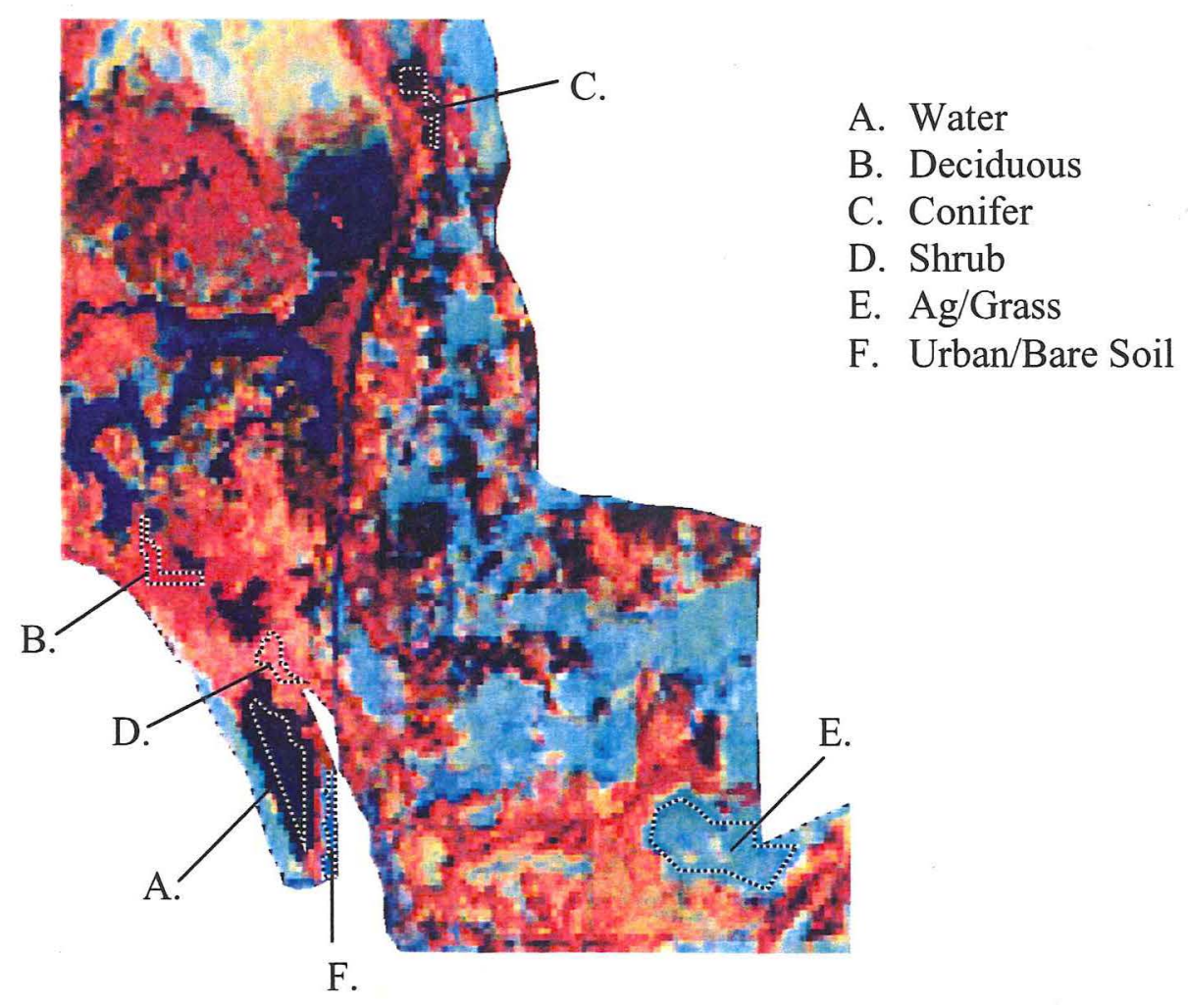


Using 60 classes, unsupervised classification was performed prior to the supervised classification in order to familiarize myself with the spectral reflectance patterns present within the image, and to help guide in choosing appropriate training sites. Several band combinations, including, 321, 432, and 453 for red, green, and blue display channels were utilized in determining appropriate training sites for the supervised classification (Figure 3). Reference datasets were also employed during the classification procedure, including an August $15^{\text {th }} 2000$ US Geological Survey (USGS) grayscale orthophoto and personal knowledge concerning the study area. Once training sites were

Figure 5: Supervised classification results

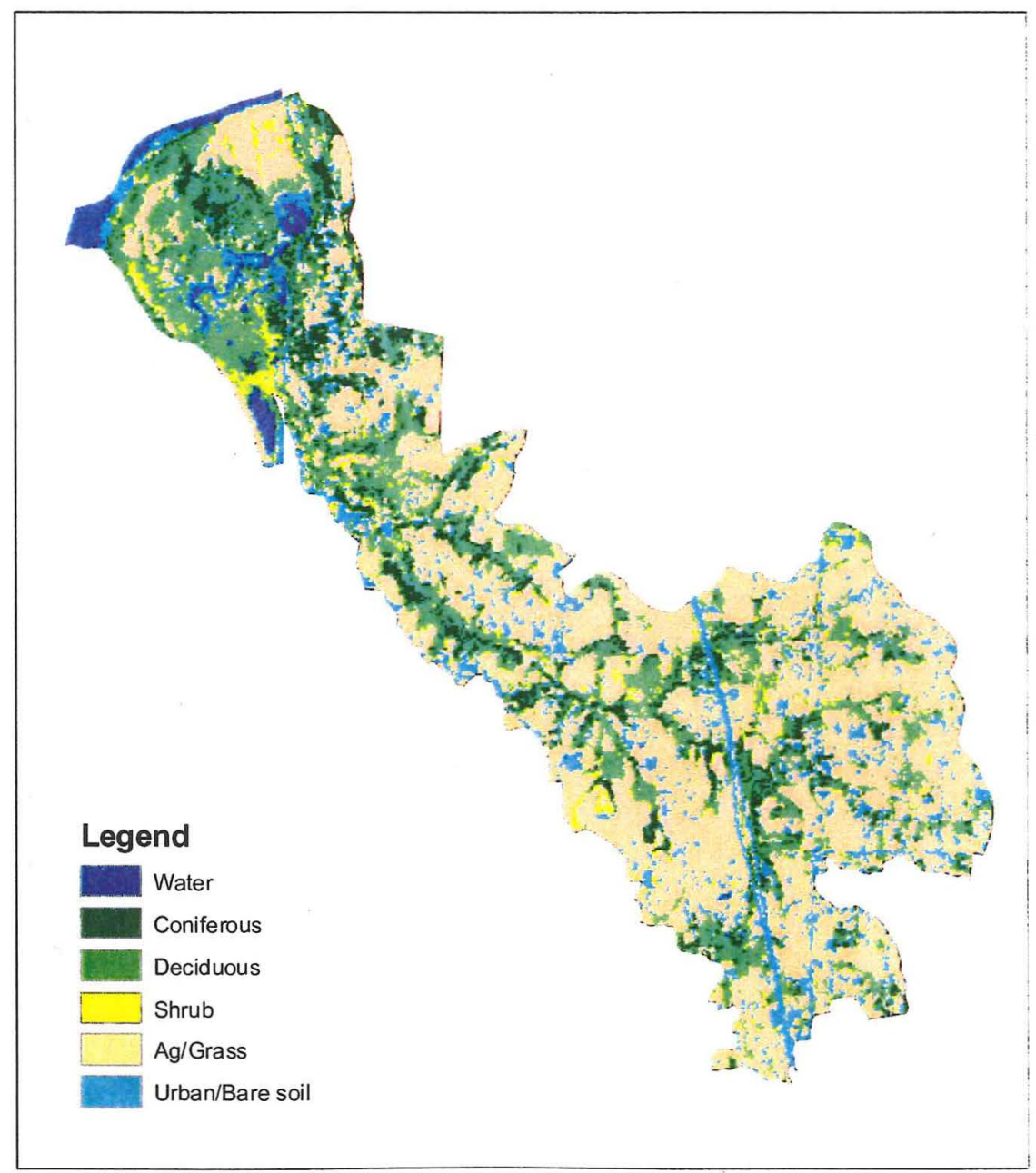


determined (Figure 4), land-cover signatures were then extracted and supervised classification was completed using the maximum likelihood classification algorithm. Initial accuracy's were checked by calculating the thresholds, which determines the variation of signatures, for each class and viewing their subsequent histograms. Initial classification results exhibited classes with off-mean or polymodal histogram distributions. As a result, the training sites used for the land-cover class in question were adjusted and the supervised classification procedure was repeated. After several iterations, acceptable thresholds were obtained, allowing for the accuracy assessment to

Figure 6: Unsupervised classification of transformed Tasseled Cap bands results

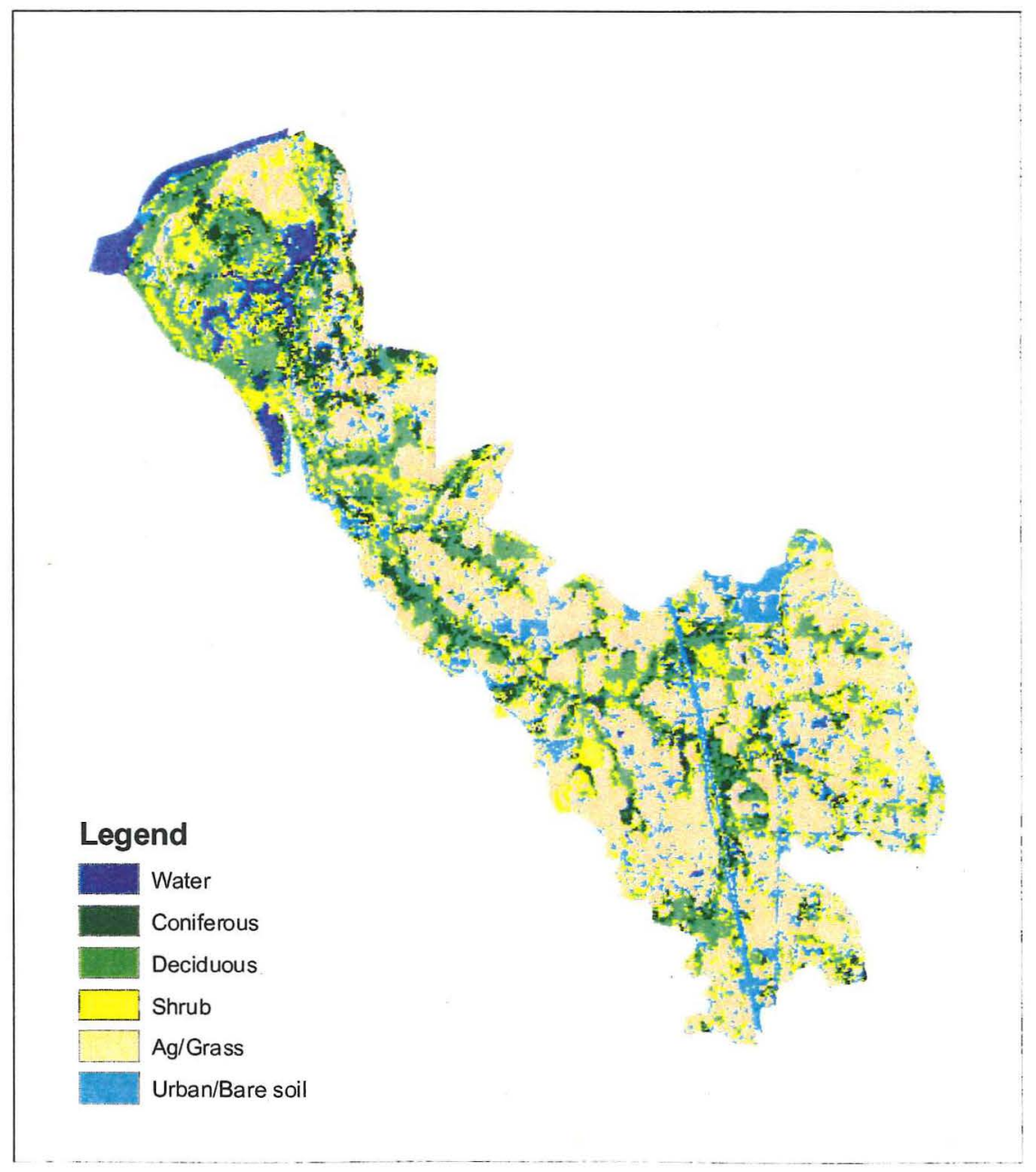


be conducted. The results of the supervised classification performed on the Gee Creek Watershed are shown in Figure 5.

To compare the results of the supervised classification with an alternative pixelbased classification method, unsupervised classification of transformed TC bands was performed on the 1999 Landsat ETM+ image. For this analysis, the $6 \mathrm{ETM}+$ bands utilized in the supervised classification method were layer stacked with transformed TC bands 1 and 2 from the 1999 Landsat ETM+ image; TC band 1 to measure brightness (measure of soil) and band 2 to measure greenness (measure of vegetation). The combined bands were used as inputs to the ISODATA unsupervised classification to generate 20 spectral classes. Each class was then visually interpreted and categorized into one of the 6 general land-cover classes, followed by an accuracy assessment. The result of the unsupervised classification of transformed Tasseled Cap bands is shown in Figure 6.

\section{Object-based Classification}

A USDA Multi-resolution Seamless Image Database (MrSID) natural color image from July 2006 was used for the object-based classification (Figure 7). The 1-meter resolution natural color image was obtained via a free download from the USDA Geospatial Data Gateway website. Environmental Systems Research Institutes (ESRI) ArcGIS desktop product ArcView 9.2 was utilized for pre- and post-processing of the object-based classification. The software product SPRING 4.3 was used to conduct the segmentation and object-based classification on the 2006 image.

Using ArcView, the 1-meter color image was masked to the boundaries of the Gee Creek Watershed. The 2006 image was then imported into SPRING and varying 
levels of segmentation were applied using the Region Growing method ${ }^{1}$. In order to determine the appropriate level of segmentation hierarchy that should be applied to the image, various values were used for Similarity and Area size ${ }^{2}$. The goal in doing so was to choose a level of hierarchy that captured the smallest feature size desired in the landcover classification (a result of the Area value), while limiting over-segmentation due to choosing too low of a Similarity value. Figure 8 shows examples of the three levels of segmentation hierarchy considered for object-based classification in this analysis.

Through experimentation and visual interpretation, it was determined that a Similarity

Figure 7: USDA July 2006 orthophoto

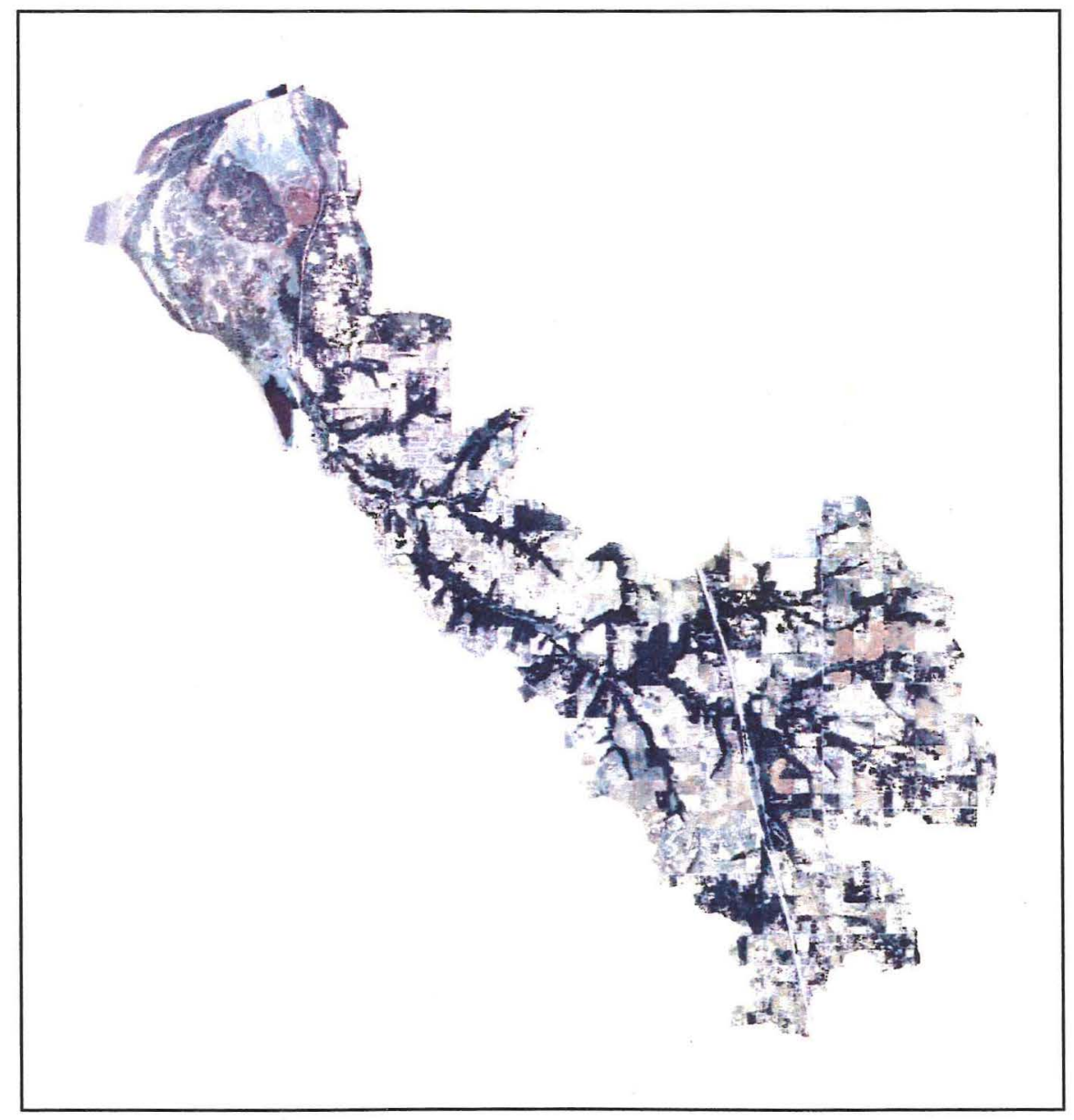


Figure 8: Three levels of segmentation hierarchy considered in analysis

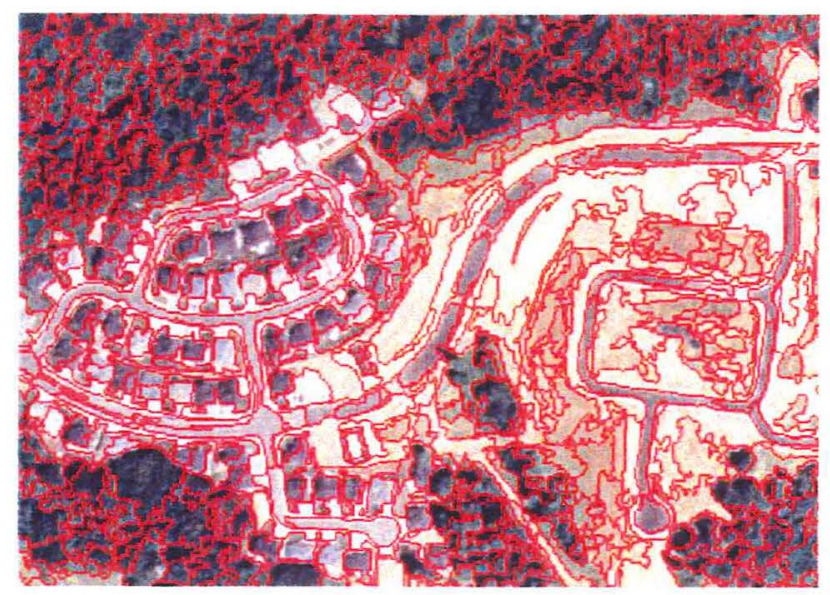

(a) Similarity Value $=10$, Area Value $=150$

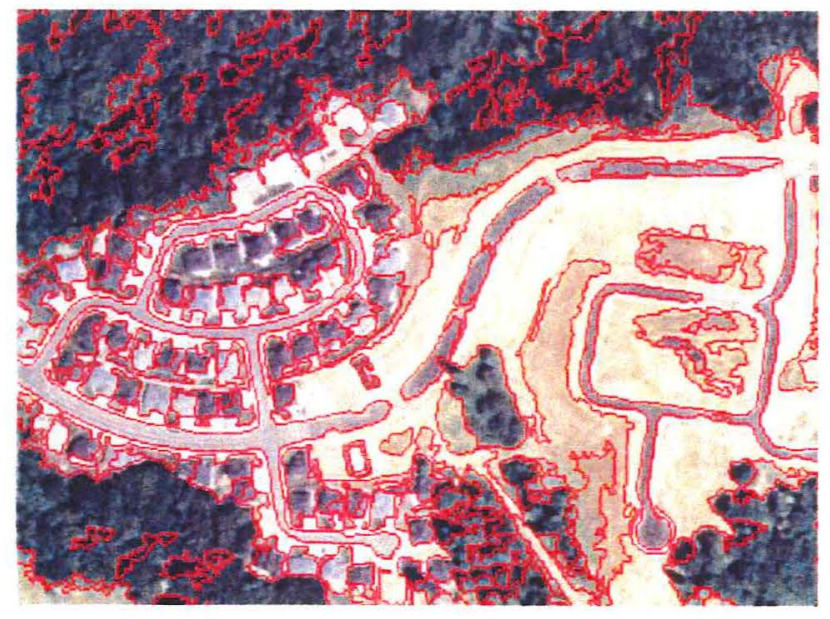

(b) Similarity Value $=35$, Area Value $=150$

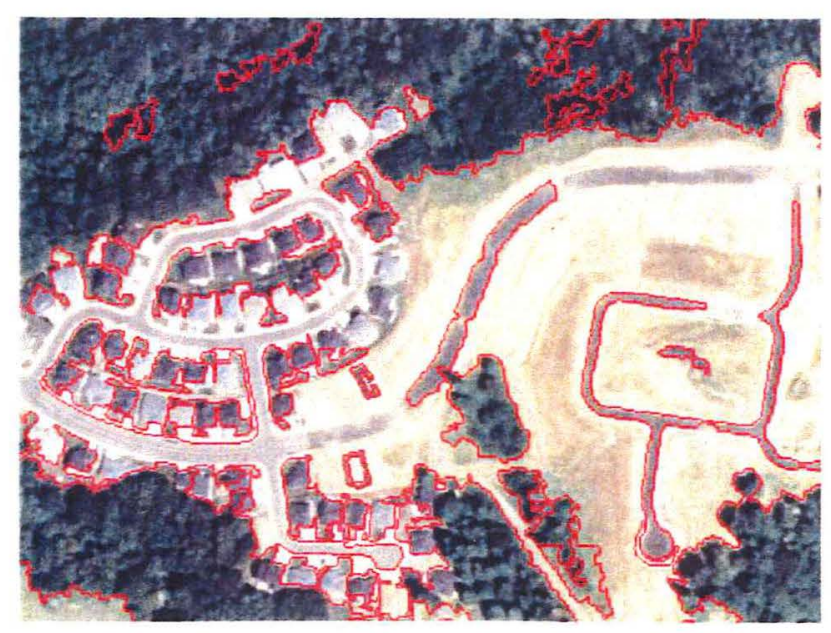

(c) Similarity Value $=60$, Area Value $=150$ 
value of 35 and an Area size of 150 were most appropriate for use in classifying the image (Figure 8.b).

In preparation for classification, the land-cover scheme used in the pixel-based approach was utilized. However, since the object-based approach utilized highresolution imagery, two land-cover classes used in the pixel-based approach were split into two, separating urban and bare land and differentiating between agricultural and large areas of Reed Canary grass located on the standing water portions of the RNWR. The eight land-cover classes utilized in the object-based approach are shown in Table 2 (right column).

Figure 9: Object-based classification results

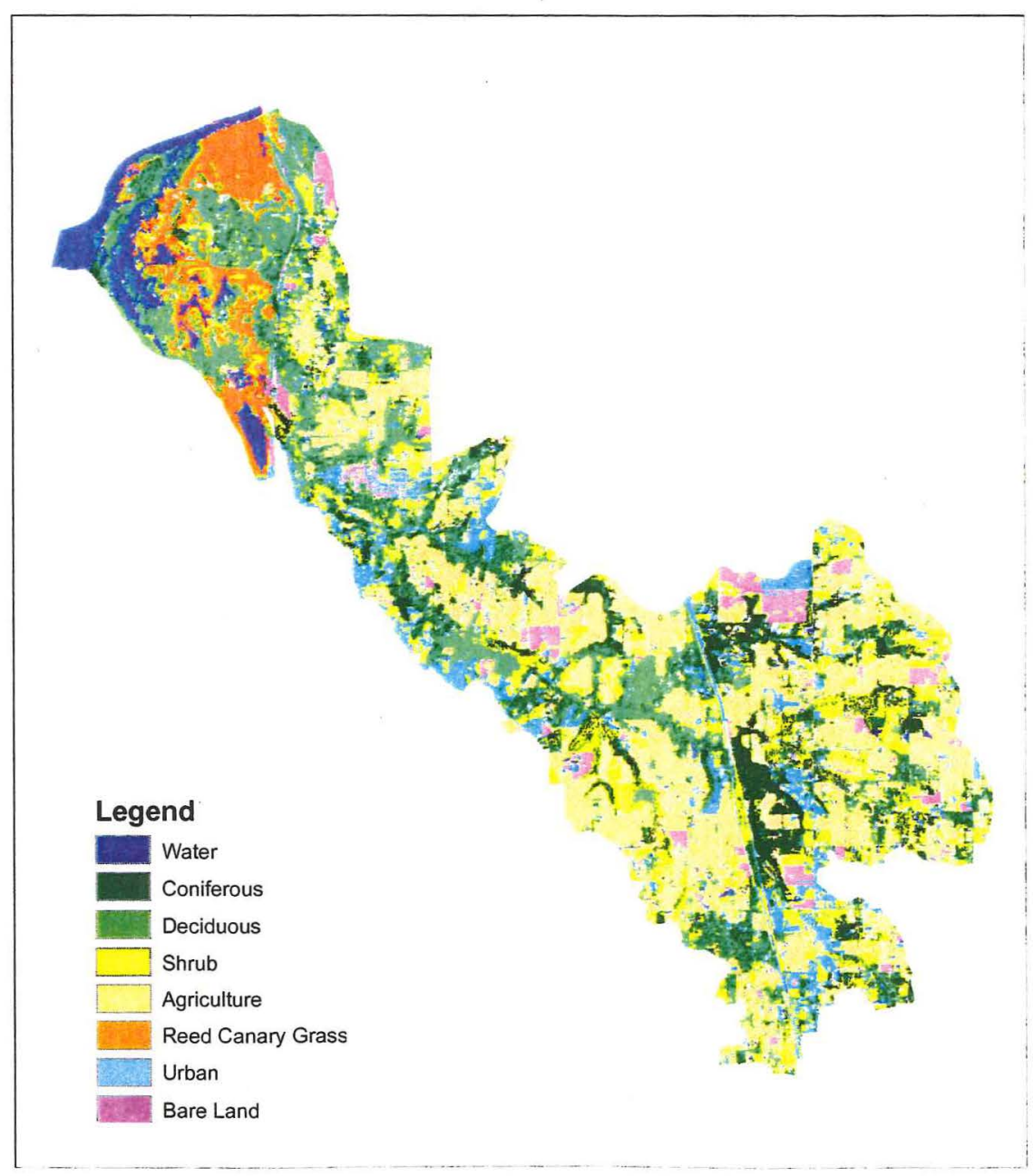


Similar to pixel-based supervised classification, the object-based classification approach used in this study also requires the selection of training sites. Once training sites were established for each of the eight classes, the region classifier Bhattacharya was applied $^{3}$. The classified land-covers (Figure 9) were exported from SPRING and into the ArcGIS environment for conducting the accuracy assessment and calculating summary statistics.

\section{Accuracy of Classification Results}

To determine the accuracy of the pixel-based supervised classification, a stratified random sampling scheme including 180 pixels was applied and their agreement with ground truth was analyzed through the visual interpretation of the 1999 Landsat ETM+ and August $15^{\text {th }} 2000$ USGS grayscale orthophoto. A minimum of 20 points were applied to each class to assure that all land-cover classes were included in the accuracy assessment. The stratified random sampling method was chosen for overcoming the shortcomings of random sampling, which tend to over-represent abundant classes that cover more area and have a higher probability of containing sample sites (Goodchild et al, 1994). The results of the accuracy assessment (Table 3) show that deciduous and shrub land-cover classes had the lowest combined producer and user accuracy's. Overall, an accuracy of $73 \%$ was obtained for the supervised classification approach.

To assess the accuracy of the unsupervised classification using transformed TC bands, the stratified random sampling method employed on the supervised classification was used. The results of the accuracy assessment (Table 3) show that urban/bare land and coniferous land-cover classes had the lowest combined producer and user accuracy's. 
Table 3: Accuracy results using the pixel- and object-based classification approaches

\begin{tabular}{|c|c|c|c|c|c|c|}
\hline \multirow[b]{2}{*}{ Class Name } & \multicolumn{2}{|c|}{ Supervised } & \multicolumn{2}{|c|}{ Tasseled Cap } & \multicolumn{2}{|c|}{ Object-Based } \\
\hline & $\begin{array}{c}\text { Producer's } \\
\text { Accuracy } \\
\%\end{array}$ & $\begin{array}{c}\text { User's } \\
\text { Accuracy } \\
\%\end{array}$ & $\begin{array}{c}\text { Producer's } \\
\text { Accuracy } \\
\%\end{array}$ & $\begin{array}{c}\text { User's } \\
\text { Accuracy } \\
\%\end{array}$ & $\begin{array}{c}\text { Producer's } \\
\text { Accuracy } \\
\%\end{array}$ & $\begin{array}{c}\text { User's } \\
\text { Accuracy } \\
\%\end{array}$ \\
\hline Water & 90 & 90 & 77.78 & 87.5 & 98.7 & 96.5 \\
\hline Coniferous & 66.67 & 69.57 & 65 & 76.47 & 99.96 & 67.3 \\
\hline Deciduous & 69.05 & 76.32 & 85.54 & 72.15 & 100 & 100 \\
\hline Shrub & 58.28 & 70 & 60.18 & 79.76 & 89.17 & 68.8 \\
\hline \multirow{2}{*}{$\begin{array}{l}\text { Agriculture } \\
\text { Grass (Reed Canary) }\end{array}$} & \multirow{2}{*}{90} & \multirow{2}{*}{67.92} & \multirow{2}{*}{90.64} & \multirow{2}{*}{80.63} & 99.32 & 100 \\
\hline & & & & & 85.03 & 100 \\
\hline \multirow{2}{*}{$\begin{array}{l}\text { Urban } \\
\text { Bare Land } \\
\end{array}$} & \multirow{2}{*}{76} & \multirow{2}{*}{73.08} & \multirow{2}{*}{66.67} & \multirow{2}{*}{72.22} & 85.44 & 67.67 \\
\hline & & & & & 93.32 & 100 \\
\hline Overall Accuracy & \multicolumn{2}{|c|}{$73 \%$} & \multicolumn{2}{|c|}{$76 \%$} & \multicolumn{2}{|c|}{$88 \%$} \\
\hline
\end{tabular}

An overall accuracy of $76 \%$ was obtained for the unsupervised classification of transformed TC bands approach.

Table 4 shows that both pixel-based classification approaches yielded considerably different values for the total area of land-covers classified. The largest discrepancies between the two pixel-based approaches are between the shrub, agriculture/grass, and water land-cover classes. Such a large variance in total areas for the land-cover classes puts the appropriateness of the Landsat ETM+ imagery resolution and pixel-based methodologies in question.

Table 4: Total area of classified land-covers using the pixel- and object-based approaches

\begin{tabular}{|c|c|c|c|}
\hline \multirow[b]{2}{*}{ Class Name } & \multicolumn{3}{|c|}{ Area (in acres) } \\
\hline & $\begin{array}{c}\text { Supervised } \\
\text { Classification }\end{array}$ & $\begin{array}{l}\text { Tasseled } \\
\text { Cap }\end{array}$ & $\begin{array}{l}\text { Object- } \\
\text { Based }\end{array}$ \\
\hline Water & 246 & 456 & 490 \\
\hline Coniferous & 762 & 611 & 1211 \\
\hline Deciduous & 2914 & 2175 & 2230 \\
\hline Shrub & 258 & 1742 & 1563 \\
\hline Agriculture & \multirow{2}{*}{5266} & \multirow{2}{*}{4278} & 3145 \\
\hline Grass (Reed Canary) & & & 647 \\
\hline Urban & \multirow{2}{*}{1220} & \multirow{2}{*}{1404} & 972 \\
\hline Bare Land & & & 408 \\
\hline
\end{tabular}


To assess the accuracy of the object-based approach, an accuracy assessment similar to the pixel-based approach was utilized. A stratified random sampling scheme including 180 pixels was applied. Unfortunately, to ensure that all land-covers classes in the object-based approach were incorporated into the accuracy assessment, the 180 sample locations used in the pixel-based approach could not be replicated. The results of the object-based approach are shown in Table 3, which shows both the producer's and user's accuracy values. The object-based classification approach yielded much higher accuracy results, with an overall accuracy of $88 \%$ being obtained.

The total areas of land-covers produced in the object-based classification are provided in Table 4 . Noticeable difference between the pixel- and object-based classification results are the object-based reporting significantly greater coniferous forest and less overall agriculture (including Reed Canary grass). However, given the differences in the overall accuracy's obtained and in imagery resolution and acquisition dates, comparing total areas of land-covers classified by each approach is not appropriate as a basis for determining classification accuracy. Most important, the pixel-based approaches utilize a 1999 image, whereas the object-based approach utilizes a 2006 image. A seven year difference in imagery will clearly have differences in total landcovers due to changes in land-use.

The total area of water classified by the object-based classification is larger area than that classified by the pixel-based approaches. This can be explained in part by the July acquisition date of the USDA imagery used for the object-based approach (versus the September image used in the pixel-based approach), which corresponds to midsummer when larger expanses of standing water are present on the RNWR. In addition, 
the classified Reed Canary grass land-cover is vegetation that exists only on the refuge and can be associated with shallow standing water from spring to mid-summer (Figure 10). In contrast, the Landsat ETM+ imagery has an acquisition date of September, corresponding to late summer when standing water has receded on the refuge.

A second explanation for differences in the total area of water classified between the pixel- and object-based approaches can be explained by the multispectral bands

Figure 10: Comparing pixel- and object-based classification methods on the RNWR: a) 1999 Landsat (band combination 453), b) 1999 supervised classification, c) 1999 TC, d) 2006 USDA NAIP, e) 2006 object-based classification
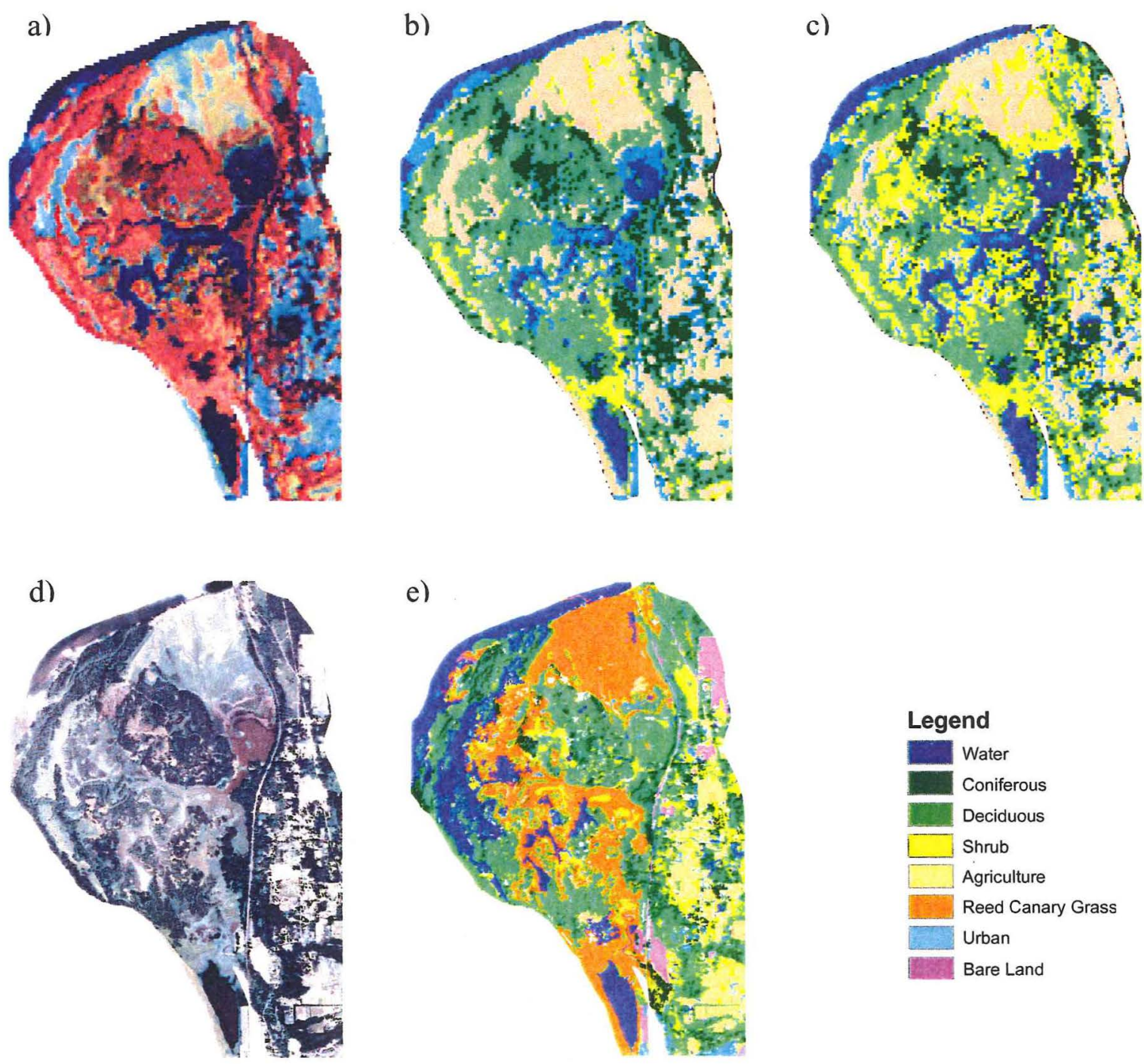
available in the Landsat $\mathrm{ETM}+$ image during classification. A visual comparison of the results of the classification approaches for the RNWR is shown in Figure 10. As shown, the use of the Landsat ETM+ Band 1 (blue) in the pixel-based approaches appear to have an easier time at classifying water bodies located on the RNWR, even with the coarser resolution satellite imagery. In contrast, the object-based approach had a more difficult time distinguishing between water, dark vegetation, and Reed Canary grass during the classification process, due to the absence of near infrared bands. As a result, it appears that the pixel-based approach utilizing Landsat ETM+ imagery may be as a minimum comparable in terms of accuracy to the object-based approach in classifying water.

In general, the effectiveness of the object-based approach over the pixel-based approaches is evident in areas of the Gee Creek Watershed that exhibit highly variable landscapes over short distances. For example, Figure 11 provides a visual comparison of a section of the watershed's landscape that exhibits coniferous, deciduous, shrub, agriculture, and urban land-covers over a distance of approximately 0.5 miles. As shown, the pixel-based approaches over generalized these areas due to the coarse 30 -meter resolution inherent in the Landsat ETM+ imagery. In contrast, the use of the objectbased approach allowed for accurate differentiation between the highly diversified landscapes, as shown in Figure11. Note the recent development in the center of the 2006 USDA NAIP image and the ability of the object-based approach to differentiate between the bare soils and urban streets within the new development. The higher accuracy is in part the result of using 1-meter resolution imagery which allows for the classification of finer detailed objects in the image. In fact, the use of 1-meter aerial imagery results in 
approximately 812 pixels to cover the same area covered by one pixel in the 30 -meter Landsat imagery.

Figure 11: Comparing pixel- and object-based classification methods on the RNWR: a) 1999 Landsat (band combination 453), b) 1999 supervised classification, c) 1999 TC, d) 2006 USDA NAIP, e) 2006 object-based approach

a)

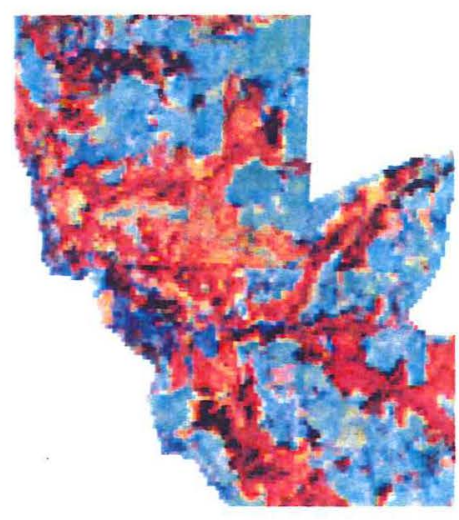

d)

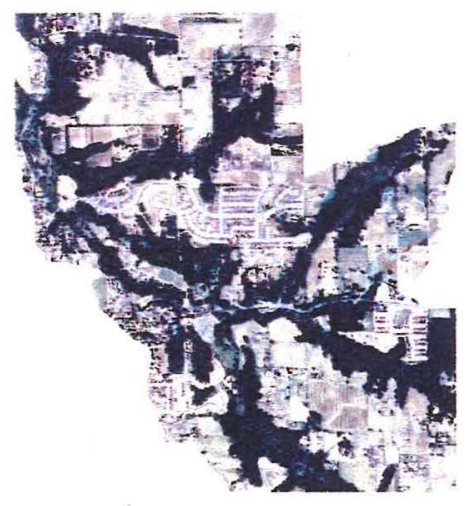

b)

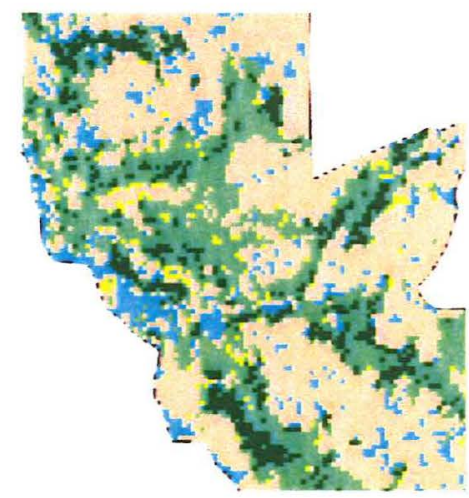

e)

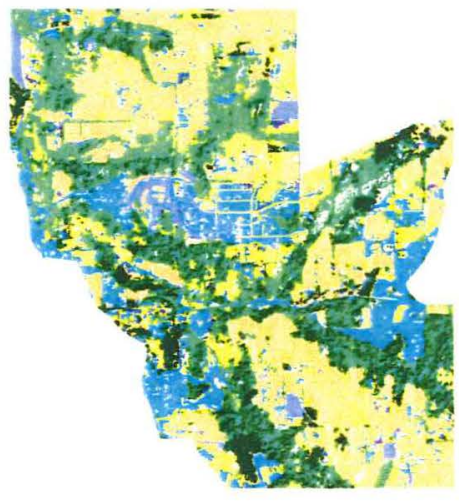

c)

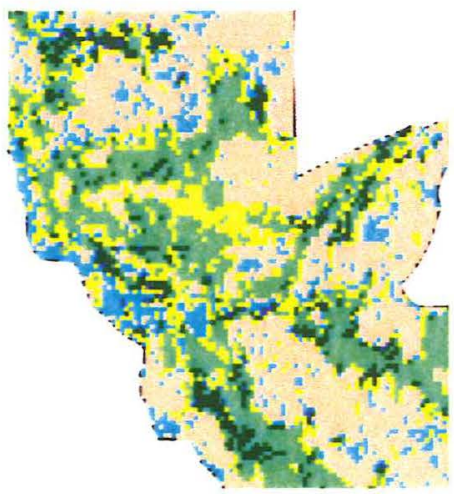

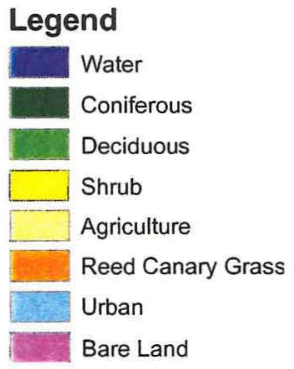

\section{Conclusion}

Using the Gee Creek Watershed as a case study, this paper examined and compared two traditional pixel-based land-cover detection methods with the object-based approach. Due to resolution limitations inherent in the Landsat imagery, the pixel-based approach resulted in limited accuracy on six general land-cover classes. The 30-meter 
resolution Landsat imagery can be utilized for watershed studies, however when dealing with highly variable land-cover types, as with the Gee Creek Watershed, only general land-covers should be classified. One potential suggestion for improving the pixel-based approach in distinguishing between coniferous and deciduous land-covers would be to acquire satellite imagery that corresponds to 'leaf-off' times of the year. For example, satellite imagery with an acquisition date of January could be utilized, allowing for potentially easier differentiation and classification of coniferous and deciduous landcovers.

The use of Landsat imagery also over generalized the watershed's landscape, making the establishment of reliable training sites and conducting the accuracy assessment through visual interpretation very difficult. Higher resolution satellite imagery, such a Quickbird, would be required in order to properly classify a larger range of land-cover classes at a finer spatial scale. The object-based analysis method (e.g. segmentation) is more effective for classifying land-cover types within the Gee Creek Watershed using high-resolution imagery.

The object-based approach to classifying land-covers using high-resolution imagery resulted in the distinction of additional land-cover types and a higher overall accuracy. The high classification accuracy obtained is primarily a function of image resolution. However, as this study shows, the object-based approach may prove to be a reliable method for classifying land-covers using imagery with differing resolutions. More importantly, the highly detailed land-covers classified using the object-based approach has far greater utility, enabling its use with high-resolution ancillary data for further mapping and analysis. 
The results of this analysis suggests that Landsat imagery is only suitable for determining general land-cover types, such as combining urban and bare land into one land-cover class. In contrast, the use of object-based classification resulted in increased accuracy and ultimately led to a higher number of land-cover classes being distinguished, including the differentiation between agriculture and Reed Canary grass and between bare land and urban land-covers. As a result, when mapping spatially complex landscapes with high-resolution aerial imagery, object-based classification methods utilizing image segmentation and region-based classifiers are expected to be more suitable than traditional pixel-based classification approaches. Future studies in the Gee Creek Watershed will include change detection between historical and current land uses, which further suggests that the use of an object-based classification approach will ultimately lead to better change detection results. 


\section{Notes}

1. The Region Growing method is a data grouping technique that allows only spatially adjacent regions to be grouped. Initially, the segmentation process labels each pixel as a distinct region. The similarity criteria are then computed for each spatially adjacent region, which is based on a statistical hypothesis test that checks the average among regions (Brazil's National Institute for Space Research, 2006). The image is then divided into a set of sub images and a union operation is performed, following an aggregation limit based on the user defined Similarity value.

2. The Similarity measure is based on the Euclidean distance between the average values of gray levels for each region (Brazil's National Institute for Space Research, 2006). As a result, two regions are considered different if the distance between their averages is greater than the similarity value chosen. Regions with areas smaller than the minimum Similarity value are absorbed by more similar adjacent regions. The second user defined value, the Area, represents the minimum size, in pixels, that comprises a segmented region.

3. The Bhattacharya classification algorithm calculates the statistical probability between a pair of spectral classes by measuring the average distance between the spectral classes' probability distributions (Brazil's National Institute for Space Research, 2006). 


\section{References}

Alsea Geospatial, Biosystems, and Water Work Consulting. 2004. Calapooia River Watershed Assessment. February.

Anderson, J.R., Hardy, E.E., Roach, J.T., and Witmer, R.E. 1976. A Land Use and Land Cover Classification System For Use with Remote Sensor Data: Geological Survey Professional Paper 964. Edited by NJDEP, OIRM, BGIA, 1998, 2000, 2001, 2002, 2005.

Barbosa, V., Machado, R.J., Liporace, F.S. 1993. A Neural System for Deforestation Monitoring on Landsat Images of the Amazon Region. IBM Rio Scientific Center, Technical Report CCR-157.

Bins, L., Erthal, G.J., and Fonseca, L.M.G. 1993. A Method for Non-Supervised Region Classification. In: Proceedings of VI Brazilian Symposium on Computer Graphics and Image Processing, pp 65-68.

Blaschke, T., and Strobl, J. 2002. What's wrong with pixels? Some recent developments interfacing remote sensing and GIS. GeoBIT/GIS: J. Spatial inform. Decision Making, No. 6/2001: 12-17.

Brazil's National Institute for Space Research. 2006. SPRING Help. SPRING V4.3. December.

Bureau of Land Management. 2007. Historical Survey Plats. http://plso.wadnr.gov/blm_wa/wsrvyl.asp. July.

Camara, G., Souza, R.C.M., Freitas, U.M., and Garrido, J. 1996. SPRING: Integrating Remote Sensing and GIS by object-oriented data modeling. Computers and Graphics 20(3): 1-17.

Clark County Assessment and GIS. 2007. Maps Online, The Digital Atlas. Vancouver, WA.

Clark County Public Works, Clean Water Program. 2004. Clark County Stream Health Report. Vancouver, WA.

Clarke, S., Dent, L., Measeles, P., Nierenberg, T., and Runyon, J. 2004. Oregon Riparian Assessment Framework. July.

Columbian Newspaper, Vancouver WA. 1953. "City is 4th Largest In County Area" article by Bill Knight. 'Ridgefield' box file, Clark County Historical Museum, Ridgefield, WA. July 31. 
Cornelius, L. 2006. Gee Creek Watershed Restoration Background Report. July. . 2007. In Person Interviews. United States Fish and Wildlife. June - August. .2008. In Person Interviews. United States Fish and Wildlife. April.

Definiens Imaging. 2001. eCognition User Guide.

Fort Vancouver Historical Society, 1961-1965. Clark County History, Vols 1, 1960 to 5, 1965. Vancouver, WA.

Goodchild, M., Curtis, A., Vaughan, R., Stadelmann, M. 1994. Accuracy Assessment Procedures: NBS/NPS Vegetation Mapping Program. November.

Kettig, R. L. and Landgrebe, D. A. 1976. Classification of Multispectral Image Data by Extraction and Classification of Homogeneous Objects. IEEE Transactions on Geoscience Electronics 14(1): 19-26.

Leica Geosystems Geospatial Imaging, LLC. 2005. ERDAS Field Guide.

Lewinski, S and Zaremski, K. 2004. Examples of Object-Oriented Classification Performed On High-Resolution Satellite Images. Miscellanea Geographica 11: 349358.

Meinel, G., Neubert, M. and Reder, J. 2001. The potential use of very high resolution satellite data for urban areas - First experiences with IKONOS data, their classification and application in urban planning and environmental monitoring. In: Remote Sensing of Urban Areas. Regensburger Geographische Schriften, pp 196-205.

Meinel, G. and Neubert, M. 2004. A Comparison of Segmentation Programs for High Resolution Remote Sensing Data. Leibniz Institute of Ecological and Regional Development (IOER), Weberplatz 1, D-01217 Dresden, Germany.

Oruc, M., Marangoz, A.M. and Buyoikalih, G. 2006. Comparison of Pixel-Based and Object-Oriented Classification Approaches Using Landsat-7 ETM Spectral Bands. TUBITAK (Turkey) - JULICH (Germany) cooperation with a code no. 101 Y090 and Karaelmas University project no. 2001/45-01.

Ridgefield, City of. 2006. City Ordinances Nos. 664, 732, and 868. Ridgefield, WA.

Schnabel, J. 2005. Whipple Creek Stream Assessment Summary. July.

Souza Camara G., Freitas, UM. and Garrido J. 1996. SPRING: Integrating remote sensing and GIS by object-oriented data modeling. Computers \& Graphics 20(3): 395-403. May-June. 
Traux, D.D., Repaka, S.R., Kolstad, E., O'Hara, C.G. 2006. Report: Comparing Spectral and Object Based Approaches for Classification and Transportation Feature Extraction from High Resolution Multispectral Imagery. Department of Civil Engineering, Mississippi State University.

United States Fish and Wildlife Service. 2004. Gee Creek Restoration Alternatives at Ridgefield National Wildlife Refuge. May. 2006. Vegetation/Habitat Mapping: Object Based Image Classification Using SPRING Software. February.

Watershed Professionals Network. 1999. Oregon Watershed Assessment Manual. July.

Welch, RA. 1982. Spatial Resolution Requirements for Urban Studies. International Journal of Remote Sensing 3: 139-146. 